\title{
The diagnosis and management of hyperparathyroidism during pregnancy
}

\author{
Alexander A. Deutsch* \\ M.B. Ch.B., F.R.C.S. (Eng), F.R.C.S. (Ed) \\ JACQUES BERNHEIM $\dagger$
M.D.
}

\author{
MORDECHAI ZAGER* \\ M.D.
}

ZEV STEINER**

M.D.

\author{
RAPHAEL REISS* \\ M.D. \\ *Departments of Surgery B, **Internal Medicine B and the †Nephrology Unit, Meir General Hospital, \\ Affiliated to Tel Aviv University Medical School
}

\begin{abstract}
Summary
Hyperparathyroidism during pregnancy is rare and very few cases have undergone parathyroidectomy during the course of gestation. In reviewing the literature it is apparent that surgery during the second trimester should be the treatment of choice. The complication rate of untreated cases may reach $80 \%$ and include spontaneous abortion, fetal death and neonatal tetany. The paper is illustrated with appropriate cases.
\end{abstract}

\section{Introduction}

In recent years there has been increasing awareness of hyperparathyroidism in asymptomatic patients. This is particularly so following the Stockholm study (Christensson et al., 1976) in which $0.36 \%$ of 15903 of a randomly studied population was found to suffer from hyperparathyroidism.

Hyperparathyroidism in pregnancy is still a rare occurrence. Only 42 cases have been described in the literature and 9 of those underwent a parathyroidectomy during the course of their pregnancy.

If surgical treatment is not undertaken during the pregnancy, there is a high rate of fetal complications including fetal death, abortion and neonatal tetany.

In reviewing the literature it can be seen that there is a striking improvement in the prognosis of the fetus if parathyroidectomy is performed during the pregnancy.

Ludwig (1962) reviewed 21 cases including 2 of his own. These women had 39 pregnancies of which 20 were normal and 19 were complicated, almost $50 \%$. The complications included fetal death and spontaneous abortions in $31 \%$ and neonatal tetany in $19 \%$.
Only rarely has the diagnosis been made during the pregnancy, and neonatal tetany is often the first clinical sign. Only in one of Ludwig's group was a parathyroidectomy performed during pregnancy, with a normal subsequent course to the mother and infant.

Delmonico et al. (1976) reviewed all cases from 1962-1977 and found 13 cases with 15 pregnancies who did not have surgery and a further 8 cases who had a parathyroidectomy performed during the pregnancy.

In the non-operated group, the complication rate reached $80 \%$. Eight had neonatal tetany, one had neonatal hypocalcaemia requiring treatment, in one case there was a spontaneous abortion and in a further case there was a stillbirth.

In the same group of 13 women there was a total of 36 previous pregnancies with a $19.4 \%$ fetal complication rate. This would be in keeping with asymptomatic hyperparathyroidism in a number of these women, as the average complication rate should not be above $10 \%$ (Jeffcoate, 1962).

Gaeke et al (1977) added a further case of hyperparathyroidism during pregnancy who underwent parathyroidectomy in the 17th week of gestation. This resulted in a normal subsequent pregnancy and infant. A further case is presented to illustrate the management of this condition.

\section{Method}

Parathyroid immunoassay was performed using the guinea-pig antibody $(\mathrm{O} 3)$ raised against bovine parathyroid hormone (PTH). The antibody recognizes both 9500 and 7000 molecular weight portions of the hormone with the C-terminal site antigen. 
Iodination of the hormone was achieved by the technique of Hunter and Greenwood (1962). The incubation procedure was similar to that described by Arnaud, Tsao and Littledyke (1971) and separation of bound and free portions was obtained using activated Charcoal-Dextran as described by Bernheim and David (1974). Normal values for PTH in the authors' laboratory are less than $850 \mathrm{pg} / \mathrm{ml}(\equiv 2 \cdot 3$ i.u., IRE kit).

\section{Case report}

A 25-year-old mother of a 2-year-old child was admitted to the medical ward in the sixth month of her pregnancy. During routine ante-natal care she was found to have BP readings of $140 / 100$ and $150 / 110 \mathrm{mmHg}$ on separate occasions. She complained of recent dizziness and weakness and had been treated with iron and folic acid. There was no ankle swelling or proteinuria.

During her previous pregnancy she had been treated for mild hypertension, but the pregnancy and delivery were uneventful and the infant was normal.

Physical examination revealed no abnormality.

TABLE 1. Hyperparathyroidism in pregnancy

\begin{tabular}{ll}
\hline \multicolumn{2}{c}{ Laboratory investigations-Case report } \\
\hline Serum calcium & $11 \cdot 0,11 \cdot 5 \mathrm{~g} / \mathrm{dl}$ \\
Serum phosphorus & $1 \cdot 7,2 \cdot 2 \mathrm{~g} / \mathrm{dl}$ \\
Serum chloride & $109 \mathrm{mEq} / 1$ \\
Serum parathyroid hormone & $850 \mathrm{pg} / \mathrm{ml}$ \\
Tubular reabsorption of phosphorus & $55 \%, 70 \%$ \\
24-hr urine calcium excretion & $51 \mathrm{mmol} / 24 \mathrm{hr}$ \\
24-hr VMA & Normal \\
\hline
\end{tabular}

Routine urine and blood tests were within normal气 limits. More careful examination of blood and urine 3 (Table 1) revealed hypercalcaemia, hypophospha- $\varrho$ taemia, hyperchlorhydria and a reduced tubular. reabsorption of phosphorus. A PTH measurement was at the upper limit of normal. X-ray of the? hands showed no evidence of subperiosteal resorption? of bone and an electro-cardiograph was within $\frac{\overline{0}}{\frac{1}{6}}$ normal limits.

A diagnosis of hyperparathyroidism was made $\stackrel{\mathbb{}}{\varrho}$ and neck exploration was undertaken in the twentyfourth week of her pregnancy.

At operation an adenoma of the upper left parathyroid gland measuring $1.5 \mathrm{~cm} \times 1 \mathrm{~cm}$ (Fig. 1) was $\vec{\omega}$ found. The tumour was excised after confirmation? that the other 3 parathyroid glands were normal. $\frac{0}{3}$ Histological examination confirmed the presence of a benign adenoma of the parathyroid gland.

Postoperative blood PTH concentration fell to $300 \mathrm{pg} / \mathrm{ml}$, and the calcium level fell to $8.9 \mathrm{mg} / \mathrm{dl}$. The patient was discharged 4 days following operation.

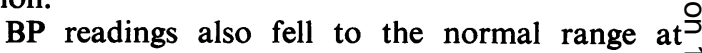
$110 / 80 \mathrm{mmHg}$.

The pregnancy progressed normally, without complications, and a normal infant boy was delivered in the 40th week of the pregnancy. The infarf, $\infty$ weighing $3.2 \mathrm{~kg}$, had normal blood calcium levels.

\section{Discussion}

When considering the 10 cases who underwent parathyroidectomy during pregnancy (Table 2), it is striking that there were so few complications. Eight $\stackrel{\mathbb{Q}}{\stackrel{\mathbb{Q}}{\circ}}$ cases delivered normally; in one instance the infant $\overrightarrow{\vec{B}}$

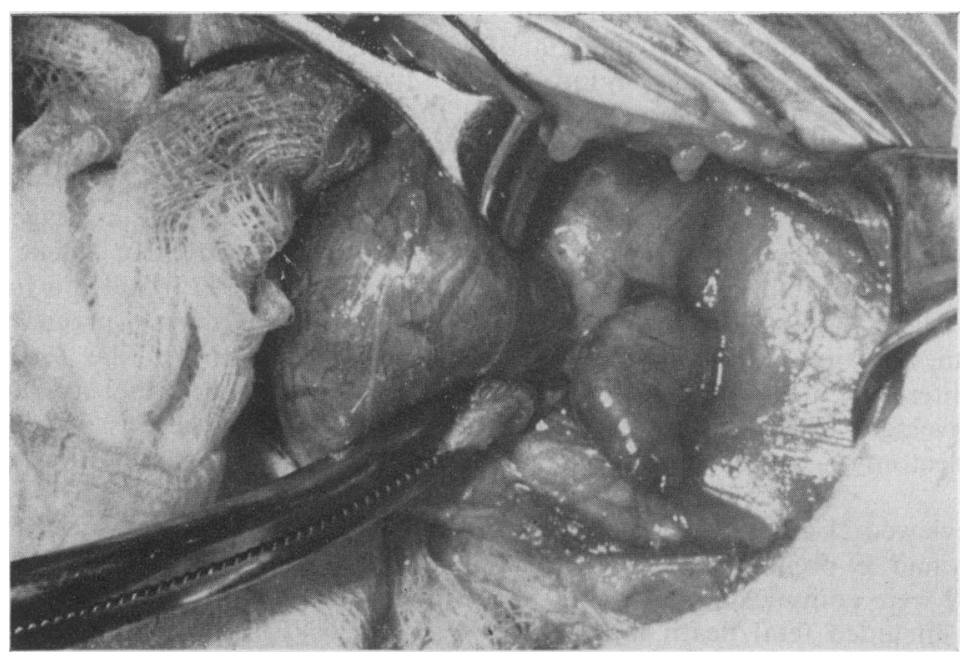

FIG. 1. Adenoma of the left upper parathyroid gland $(1 \times 1.5 \mathrm{~cm})$ (to the right of the forceps). 
TABLE 2. Hyperparathyroidism in pregnancy. Total number of cases in the literature

\begin{tabular}{ccccc}
\hline $\begin{array}{c}\text { With/without parathyroidectomy } \\
\text { during pregnancy }\end{array}$ & women & $\begin{array}{c}\text { Number of } \\
\text { pregnancies }\end{array}$ & $\begin{array}{c}\text { Normal } \\
\text { birth }\end{array}$ & $\begin{array}{c}\text { Fetal/neonatal } \\
\text { complications }\end{array}$ \\
\hline With & 10 & 10 & 8 & 2 \\
Without & 33 & 52 & 21 & 31 \\
Total & 43 & 62 & 29 & 33 \\
\hline
\end{tabular}

required supplementary calcium for a short period, and one woman underwent a spontaneous abortion $18 \mathrm{hr}$ after parathyroidectomy. It should be pointed out that this patient presented with severe disease, including polyuria, bone changes, nephrolithiasis, hypertension and vaginal bleeding. All cases of hyperparathyroidism described in the literature are summarized in Table 2.

It can thus be seen that the treatment of choice in hyperparathyroidism during pregnancy is parathyroidectomy. The optimal time should be during the second trimester, after all the fetal systems have developed, but before the third trimester when there is a greater likelihood of a preterm labour.

In addition, by avoiding surgery too near the delivery period, the fetus has time to allow recovery of his own parathyroid glands, thus reducing the risk of neonatal tetany. Fetal parathyroid suppression may occur because of calcium rather than PTH passing through the placenta to the fetus. The hypercalcaemia in the fetus may then suppress the fetal parathyroid glands (Delmonico et al., 1976).

The reason for the small number of cases of hyperparathyroidism in pregnancy may be explained by the relatively low number of women of childbearing age with hyperparathyroidism. The mean age of 73 patients in the series reported by Hecht, Gershberg and St Paul (1975) was 53 years for the whole group, 51 years for men and 54 years for women. The majority of patients were aged between 45 and 65 years.

Muller (1969) confirmed that most women affected were post-menopausal.

There has been some discussion as to whether all cases of hyperparathyroidism should undergo parathyroidectomy if they are asymptomatic (Purnell et al., 1971). There can be no doubt, however, that if pregnant, all cases should undergo surgery, whether asymptomatic or not.

It is interesting to note that both hypertension and hyperchloraemia were present in the case described. Mallette et al. (1974) described hypertension occurring in $\mathbf{3 0}$ of $\mathbf{5 7}$ cases of hyperparathyroidism. These authors also explain hyperchloraemic acidosis as a consequence of the renal effect of PTH.
In conclusion, it is desirable that all women in pregnancy have a routine serum calcium examination. This should be repeated several times when there is a history of neonatal tetany, abortion, stillbirth and hypertension.

The incidence of these complications might be reduced if more cases of hyperparathyroidism were found early.

\section{Acknowledgments}

The antibody and antigen used in the radioimmunoassay were kindly provided by Professor C. S. Anast, Colombia University, U.S.A.

\section{References}

Arnaud, C.D., Tsao, H.S. \& LitTledyke, T. (1971) Radioimmunoassay of human parathyroid hormone in serum. Journal of Clinical Investigation, 50, 21.

BernheIm, J. \& David, L. (1974) Le dosage radioimmunologique de la parathormone. Lyon médical, 232, 429.

Christensson, T., Hellstrom, K., Wengle, B., Alveryd, A. \& Wikland, B. (1976) Prevalence of hypercalcaemia in a health screening in Stockholm. Acta medica scandinavica, 200, 131.

Delmonico, F.L., Neer, R.M., Cosimi, A.B., Barnes, A.B. \& Russell, P.S. (1970) Hyperparathyroidism during pregnancy. American Journal of Surgery, 131, 328.

Gaeke, R.F., KaPlan, E.L., Lindheimer, M.D., Coe, F. \& SHEN, K. (1977) Maternal primary hyperparathyroidism of pregnancy. Journal of the American Medical Association, 238, 508.

Hecht, A., Gersberg, H. \& St Paul, H. (1975) Primary hyperparathyroidism. Journal of the American Medical Association, 233, 519.

Hunter, W.M. \& Greenwood, F.C. (1962) Preparation of iodine 131-labelled human growth hormone of high specific activity. Nature. London, 194, 495.

Jeffcoate, T.N.A. (1962) Principles of Gynaecology. 2nd edn, p. 209. Butterworth and Co., Aberdeen.

LuDwIG, G.D. (1962) Hyperparathyroidism in relation to pregnancy. New England Journal of Medicine, 267, 637.

Mallette, L.E., Bilezikian, J.P., Heath, D.A. \& Aurbach, G.D. (1974) Primary hyperparathyroidism: clinical and biochemical features. Medicine, 53, 127.

Muller, H. (1969) Sex, age and hyperparathyroidism. Lancet, i, 449.

Purnell, D.C., Smith, L.H., Scholz, D.A., Elve Back, L.R. \& ARNAUd, C.D. (1971) Primary hyperparathyroidism: a prospective clinical study. American Journal of Medicine, 50, 670. 